\title{
O MÉTOdo SuzUKI E A MOTIVAÇÃO: O PAPEL DO PROFESSOR E PAIS NA MOTIVAÇÃO DO ALUNO
}

\author{
The Suzuki Method and motivation: the \\ role of teacher and parents on student \\ motivation
}

\author{
El Método Suzuki y la motivación: el papel \\ del profesor y los padres en la motivación del \\ alumno
}

\author{
Marina Maugeri Santos \\ Universidade Estadual de Campinas \\ mamaugeri.mm@gmail.com \\ AdRiana N. A. MENDES \\ Universidade Estadual de Campinas \\ aamend65@gmail.com \\ Luiz Britto Passos Amato \\ Universidade Estadual Paulista "Júlio de Mesquita Filho" \\ lamato@terra.com.br
}

\begin{abstract}
Resumo: Este trabalho vem tratar do tema da motivação do aluno na educação musical, mais especificamente a motivação no aprendizado de um instrumento musical. Seu principal objetivo foi o de investigar a relação entre as estratégias motivacionais do Método Suzuki, que é uma metodologia de ensino musical, com a Teoria da Autodeterminação, teoria da área da psicologia que aborda o tema da motivação. Neste trabalho são apresentados dados colhidos em uma pesquisa de mestrado que teve como percurso: pesquisar e organizar elementos de motivação do aluno segundo a perspectiva do Método Suzuki, realizar uma atualização desses elementos por meio de uma pesquisa com professores que utilizam o Método Suzuki e, por fim, analisar e relacionar os dados obtidos na pesquisa com a Teoria da Autodeterminação. Como resultado da pesquisa são apresentados os elementos motivacionais do Método Suzuki organizados em categorias e enriquecidos com a visão da Teoria da Autodeterminação. Este material pode ser útil a professores de música e instrumento que desejam auxiliar seus alunos a se manterem motivados em seus estudos. Os resultados obtidos também mostraram que a forma como o professor lida com o aluno e atua na aula é primordial para mantê-lo motivado.
\end{abstract}

Palavras-chave: Motivação para aprender. Método Suzuki. Teoria da Autodeterminação.

\begin{abstract}
This work deals with the theme of student motivation in music education, more specifically motivation in learning a musical instrument. The main objective is to investigate the relationship between the motivational strategies of the Suzuki Method, which is a musical teaching methodology, with the Self-Determination Theory, a theory in the field of psychology that studies motivation. This work presents data collected in a master's research work that had as its pathway: researching and organizing elements of student motivation according to the Suzuki Method perspective, updating these elements through a survey with teachers who use the Suzuki Method and, finally, to analyze and relate the data obtained in the survey with the Self-Determination Theory. As a result, the motivational elements of the Suzuki Method are presented, organized into categories and enriched with the vision of the Self-Determination Theory. This material can be useful for music and instrument teachers who want to help their students stay motivated in their studies. The results also showed that the way the teacher deals with the student and acts in the classroom is essential to keep him or her motivated.
\end{abstract}

Keywords: Motivation to learn. Suzuki Method. Self-Determination Theory. 


\begin{abstract}
Resumen: Este trabajo trata del tema de la motivación del alumno en la educación musical, específicamente la motivación en el aprendizaje de un instrumento musical. Su principal objetivo fue investigar la relación entre las estrategias motivacionales del Método Suzuki, que es una metodología de enseñanza musical, con la Teoría de la Autodeterminación, una teoría en el campo de la psicología que aborda el tema de la motivación. Este trabajo presenta datos recolectados en una investigación de maestría que tuvo como objetivo: investigar y organizar elementos de motivación del estudiante de acuerdo con la perspectiva del Método Suzuki; realizar una actualización de estos elementos a través de una investigación con docentes que utilizan el Método Suzuki; y finalmente, analizar y relacionar los datos obtenidos en la investigación con la Teoría de la Autodeterminación. Como resultado de la investigación, se presentan los elementos motivacionales del Método Suzuki, organizados en categorías y enriquecidos con la visión de la Teoría de la Autodeterminación. Este material puede ser útil para profesores de música y un instrumento para quienes quieran ayudar a sus alumnos a mantenerse motivados en sus estudios. Los resultados también demostraron que la forma en que el profesor trata al alumno y actúa en el aula es fundamental para mantenerlo motivado.
\end{abstract}

Palabras clave: Motivación para aprender. Método Suzuki. Teoría de la autodeterminación.

\title{
INTRODUÇÃO
}

Este artigo é proveniente da pesquisa de mestrado de Santos (2016) realizada no Instituto de Artes da Universidade Estadual de Campinas (Unicamp). O tema principal abordado na pesquisa é o da motivação dentro da educação musical. Um tema bastante atual e importante para os professores de música e para os professores de instrumentos, pois trata de como manter o aluno interessado na aprendizagem e empenhado no estudo. Sobre esse assunto, Araújo (2015, p. 45) defende que "a motivação é um elemento psicológico fundamental para quem vivencia a experiência musical e, sem dúvida, o elemento que garante a qualidade do envolvimento do indivíduo nesse processo". No Brasil várias pesquisas têm sido realizadas sobre esse tema, como as de Araújo, Cavalcanti e Figueiredo (2010), Cernev (2011, 2015), Engelmann e Rufini (2015), Figueiredo (2010), entre outras. ${ }^{1}$

$\mathrm{Na}$ pesquisa buscou-se estudar as propostas e estratégias motivacionais que são usadas por professores do Método Suzuki. ${ }^{2}$ Tal método de ensino musical, desenvolvido pelo professor e violinista japonês Shinichi Suzuki na década de 1930 (Ilari, 2011, p. 187), tem alcance mundial, tendo sido estimado em 2012 um número de 9.398 professores espalhados por todos os continentes (Niles, 2012, p. 34-35). Suzuki desenvolveu seu método baseado em observações e empirismo. Entretanto, atualmente muitas pesquisas nas áreas de psicologia, cognição, educação e educação musical auxiliam a fundamentar cientificamente sua proposta.

Suzuki também considerava a motivação dos alunos como um fator essencial para o seu aprendizado e desenvolvimento, sendo que o professor e os pais deveriam trabalhar juntos para manter o aluno motivado (Starr, 1976, p. 9). Durante a pesquisa foi realizado um estudo, usando a bibliografia de autoria de Shinichi Suzuki (1981, 1982, 1990, 1996, 1998, 2008) e de alguns de seus seguidores (Mills; Murphy, 1973; Starr, 1976; Wickes, 1982), focando em investigar elementos que Suzuki considerava necessários para manter os

\footnotetext{
1 Para uma revisão mais completa sobre o tema, conferir o texto de Araújo (2015).

2 A autora sempre manteve relação estreita com a metodologia, estudou por ela quando iniciante e atualmente a utiliza como professora.
} 
alunos motivados. Esses elementos de motivação extraídos da bibliografia foram classificados em cinco categorias principais, a saber, "Despertar/nutrir o desejo de tocar", "O prazer de aprender, o prazer de ensinar", "Prática em casa", "Socialização" e "Elogios e correções". Essas categorias serão apresentadas ao longo do texto. No intuito de avaliar o quanto esses fatores motivacionais ainda são válidos na visão de professores atuais do Método Suzuki, realizou-se uma pesquisa de campo por meio de um questionário baseado nas categorias de motivação que foi lançado a um grupo de professores capacitadores latino-americanos do Método Suzuki. ${ }^{3}$

Para realizar a análise dos resultados foi escolhida uma teoria motivacional da psicologia que vem sendo bastante utilizada em estudos no meio da música e da educação musical, a Teoria da Autodeterminação (TAD), desenvolvida por Ryan e Deci (Araújo, 2013, p. 112). Essa teoria tem como foco principal estudar o ser humano, sua motivação e como ela influencia e é influenciada pelo ambiente (Deci; Ryan, 2008, p. 182). Araújo (2015, p. 48) explica que a Teoria da Autodeterminação está entre algumas das importantes teorias que auxiliam tanto músicos quanto professores e estudantes a entender a motivação e a melhorar sua prática musical ou ensino. Além disso, essa teoria possibilita estudos sobre a influência dos pais, professores, pares e ambiente na motivação do aluno de música (Araújo, 2015, p. 49). A Teoria da Autodeterminação mostrou ser uma ferramenta de análise coerente com as ideias de Suzuki (2008, p. 21-27), que vê nas crianças seres suscetiveis à influência do ambiente em que vivem e das pessoas com quem convivem (pais, professores, colegas), crendo que essa influência também atinge sua disposição e vontade para o estudo do instrumento musical.

No presente artigo, primeiramente será apresentada de forma resumida a filosofia do Método Suzuki e como seus principais pilares se relacionam com pesquisas da área de cognição. Também será exposta de forma breve a Teoria da Autodeterminação e as seis miniteorias que a compõem. Por fim, serão trazidos os dados da pesquisa de Santos (2016) sobre a motivação no Método Suzuki e como estes se relacionam com a Teoria da Autodeterminação.

\section{A FILOSOFIA DO MÉTOdO SUZUKI}

O Método Suzuki foi desenvolvido pelo professor japonês Shinichi Suzuki (1898-1998), na busca de uma metodologia com a qual ele pudesse ensinar crianças pequenas a tocar violino de uma forma fácil e natural; para tanto, inspirou-se na aprendizagem da lingua materna. Em qualquer parte do mundo, independentemente do país ou cultura, essa "metodologia" 4 de aprendizagem

\footnotetext{
3 Os professores capacitadores (teacher trainers) foram os escolhidos para participar da pesquisa devido ao seu maior tempo de experiência com o Método Suzuki. Eles são professores que após uma longa formação têm a autorização da Associação Suzuki das Américas (Suzuki Association of the Americas) para dar cursos de formação no Método Suzuki para professores de música (cf. Teacher..., 2016).

4 Colocamos metodologia entre aspas porque não existe uma real metodologia, no termo científico, que "estrutura" ou "formata" como se dá o aprendizado da língua materna pelas crianças. Este é um aprendizado natural que acompanha seu desenvolvimento.
} 
é semelhante e muito eficaz, afinal, todas as crianças aprendem sua língua materna (Suzuki, 2008, p. 9-10). Suzuki observou o que envolve esse processo de aprendizado (o ambiente onde a criança está inserida, a participação dos pais, muito contato auditivo com a língua para desenvolver a fala, etc.) e, baseando-se nessas observações, desenvolveu sua metodologia de ensino de violino.

Segundo Ilari (2011, p. 187), uma das mais relevantes contribuições de Shinichi Suzuki foi refutar a crença, muito vigente na época, de que o talento inato seria exclusivo de alguns superdotados. Para Suzuki o talento era adquirido através de estudo e dedicação. Assim, a máxima do Método Suzuki está em que toda criança possui potencial para se desenvolver musicalmente. Por isso, Suzuki nomeia o seu método de Educação do Talento, que atualmente é mais conhecido por Método Suzuki e que tem por pilares características herdadas da metodologia da língua materna, que são: introdução precoce ao aprendizado, audição, imitação, repetição, hábito do estudo diário e envolvimento dos pais que, juntamente com o professor, devem criar um ambiente propício ao aprendizado e desenvolvimento musical da criança.

Os resultados obtidos por Suzuki com sua metodologia foram tão eficazes que acabaram chamando a atenção de professores de outros países, e o Método Suzuki começou a se espalhar pelo mundo e a ser adaptado para outros instrumentos (que atualmente são: piano, violoncelo, contrabaixo, viola, flauta doce, flauta transversal, harpa, órgão, violão, trompete, voz e musicalização infanti1 ${ }^{5}$ ). Segundo Ilari (2011, p. 187), o Método Suzuki vai além da música, por ser uma "verdadeira filosofia educacional" que traz novas leituras da educação musical.

\section{O MéTOdo SuZUKI E A COGNIÇÃO MUSICAL}

Neste item serão abordados, de forma sucinta, os pilares que sustentam a filosofia do Método Suzuki sob a visão da cognição musical. Segundo David Huron (What..., 2017), a cognição musical é uma área extensa que abarca diferentes linhas de pesquisa, sendo que algumas delas aparecem no Método Suzuki, como, por exemplo, discussões sobre música e talento, música e linguagem, ensino da música e música e sociedade. Dessa forma, neste item são apresentados estudos dentro das áreas de educação musical, cognição e psicologia que reforçam o que Suzuki desenvolveu através da intuição, observação e experiência.

A primeira questão básica do Método Suzuki é a que o talento pode ser construído. Ilari (2011, p. 187) coloca essa questão na seguinte frase: "Para Suzuki o talento não é fruto do acaso, e nem uma forma de herança genética, mas sim consequência do estudo sistemático." Sobre esse assunto, Ericsson e Charness (1994, p. 729), em seu estudo sobre performance de experts, realizaram uma extensa revisão histórica sobre o mito do talento inato e das crianças

5 Cf. Browse... (2018). 
prodigios. Entretanto, ao analisarem casos reais de experts em diferentes áreas e o percurso de vida dessas pessoas que alcançaram altos níveis de performance em suas áreas, os autores chegaram à conclusão de que começar a instrução cedo, com apoio dos pais e o treinamento certo são fatores mais decisivos para se chegar ao nivel de expertise de um grande artista do que ter um talento inato. Em certo aspecto, Gardner (2007, p. 98) também compactua com as ideias de Ericsson e Charness (1994) ao apresentar sua pesquisa sobre inteligências múltiplas, colocando a inteligência musical como comum a todas as pessoas. Gardner $(2007$, p. 88) inclusive cita o trabalho de Suzuki ao afirmar que "a aquisição musical não é estritamente um reflexo de habilidade inata, mas é suscetível a estímulo e treinamento cultural".

$\mathrm{Na}$ aprendizagem da língua materna a participação e envolvimento dos pais é essencial para o desenvolvimento da fala por parte do bebê, e assim também no Método Suzuki a presença deles é muito importante para o desenvolvimento musical dos filhos. Suzuki propõe que seja formada uma relação triádica entre professor, pais e aluno na qual haja auxilio mútuo (Ilari, 2011, p. 199). Os pais devem, além de dar apoio e incentivo aos filhos, assistir às aulas para em casa poder ajudá-los a estudar, principalmente quando a criança é muito pequena. Tsitsaros (1996, p. 122, tradução nossa), ao falar sobre pedagogia e didática do ensino musical, defende a importância da relação e apoio que deve existir entre professores e pais, afirmando: "Cooperação constante entre professores e pais é essencial para assegurar que o aluno continue a entender o aprendizado e a prática da música como algo que ele anseia, em vez de algo que ele é obrigado a fazer."6

Suzuki (1981, p. 1) acreditava que quanto mais cedo a criança entrasse no mundo da música maior seria a facilidade para desenvolver aptidões musicais e até mesmo motoras, estas últimas muito importantes para se aprender um instrumento e, por isso, ele incentivava que as crianças tivessem contato com música desde bebês. Estudos atuais como o de Ilari (2002, p. 88) mostram que não só bebês podem ser estimulados musicalmente, mas também fetos dentro da barriga de suas mães, sendo que eles, mesmo durante a gestação, já possuem audição aguçada e capacidade de discernir algumas propriedades musicais como altura, ritmo, contorno melódico, etc. Tsitsaros (1996, p. 121) também defende o contato das crianças com a música desde pequenas e, para ele, o pico de curiosidade, admiração e entusiasmo que as crianças vivenciam entre 3 e 5 anos é uma ótima oportunidade para desenvolver a motivação pela música.

A audição é outro ponto crucial no Método Suzuki. Assim como no processo de aprendizado da língua materna as crianças escutam bastante antes de falar, Suzuki defende que antes de aprender uma música no instrumento a criança precisa estar com ela já internalizada por meio da escuta repetida

\footnotetext{
6 No original: "Constant cooperation between teacher and parents is essential to ensure that the student continues to perceive music learning and practicing as something he looks forward to, rather than something he is obliged to do."
} 
dessa música. Dessa forma, a criança poderá, com a ajuda do professor, buscar as notas da melodia já conhecida em seu instrumento, o que é um processo muito mais fácil do que aprender a melodia e concomitantemente tocá-la no instrumento (Wickes, 1982, p. 23). Suzuki acreditava que aprender um instrumento é uma tarefa em si já bastante complexa, preferindo postergar o aprendizado da leitura de partitura. Do mesmo modo, McPherson e Gabrielsson (2002, p. 101-102) mostram a opinião de diversos educadores e pedagogos musicais que defendem o mesmo argumento de Suzuki, falando, por exemplo, que o aprendizado musical por meio da imitação é muito natural para as crianças, uma vez que as habilidades na primeira infância são adquiridas por meio da imitação.

Um importante ponto ainda a destacar é que no Método Suzuki os alunos participam de aulas individuais e de aulas em grupo. Nas aulas individuais é quando aprendem a tocar o instrumento, quando o professor foca em questões posturais, técnicas, de afinação, entre outras. Já nas aulas em grupo as crianças trabalham o "tocar em grupo", que, diferentemente de tocar sozinho ou com o professor, são momentos em que acontece a socialização com outros alunos, um ponto crucial da metodologia: "Elas tocam junto com as crianças mais adiantadas, e essa influência traz um enorme e maravilhoso beneficio para o aprendizado delas" (Suzuki, 2008, p. 127). Tourinho (2007, p. 2), professora de violão da Universidade Federal da Bahia (UFBA), estudiosa do ensino coletivo de instrumentos, defende que o ensino coletivo permite que o aluno aprenda por meio da observação, imitação e socialização, além de ser uma poderosa ferramenta motivacional, assunto este que será mais detalhado adiante.

\section{A TEORIA DA AUTODETERMINAÇÃO}

A Teoria da Autodeterminação (TAD) vem sendo desenvolvida desde a década de 1970 por Deci e Ryan (2008, p. 182) e tem como principal objetivo o estudo da relação entre o ambiente e a motivação dos seres humanos. Nessa teoria são estudados os diferentes tipos de motivação que levam as pessoas a realizar determinada ação. A distinção mais comum que geralmente é feita é entre a motivação intrínseca e a motivação extrínseca. A primeira é inerente à pessoa, quando ela realiza determinada ação/atividade pelo prazer que a própria atividade/ação proporciona. No segundo caso a ação/atividade é realizada por motivos externos. Em muitas teorias a motivação extrínseca é tida como um tipo mais fraco de motivação, contrapondo-se à motivação intrínseca. Entretanto, para Ryan e Deci (2000, p. 55), a motivação extrínseca possui vários níveis de regulação, podendo resultar em uma forma motivacional fraca e superficial ou em uma motivação internalizada possuidora de características tão boas quanto a motivação intrínseca.

Por isso, a TAD propõe uma nova diferenciação entre as motivações: a motivação autônoma, que envolve a motivação intrínseca e as formas motivacionais internalizadas (originalmente extrinsecas) e acontece quando a pessoa se sente responsável pelas próprias escolhas; a motivação controlada, 
que é caracterizada pelos tipos mais fracos de motivação extrinseca e ocorre quando a pessoa se sente pressionada a realizar determinada ação; e a desmotivação, que é a falta de motivação ou intenção, de natureza oposta às outras duas (Deci; Ryan, 2008, p. 182). A TAD é considerada uma macroteoria, pois é formada por seis miniteorias que se relacionam entre si e se complementam.

Na Teoria das Necessidades Básicas (TNB) temos o conceito de que todos os seres humanos possuem três necessidades psicológicas básicas que quando satisfeitas promovem bem-estar e saúde psicológica (Deci; Ryan, 2008, p. 183). A necessidade de autonomia está relacionada ao desejo de agir segundo as próprias vontades, quando a pessoa sente que são seus próprios interesses que guiam suas ações e quando ela tem possibilidade de escolha. A necessidade de competência tem relação com o desejo de se sentir efetivo e de exercitar suas capacidades e habilidades. A necessidade de pertencer (ou de pertencimento) se refere ao desejo de estar conectado a outras pessoas, de se sentir valorizado seja por um indivíduo, seja por um grupo (Reeve, 2006a, p. 64-81).

A Teoria da Avaliação Cognitiva (TAC) estuda como eventos externos afetam a motivação intrínseca através da influência que exercem sobre as três necessidades psicológicas básicas da TNB. Estudos realizados com base na TAC mostraram que eventos de cunho informativo (e.g. feedback positivo, promoção de escolha, empatia) elevam os niveis de motivação intrínseca, enquanto eventos de cunho controlador (e.g. recompensas, punições, prazos, competição, feedback negativo) tendem a diminuir os níveis de motivação intrínseca (Ryan; Deci, 2004, p. 11). Segundo Ryan e Deci (2000) a motivação intrinseca tem um papel importante no desenvolvimento cognitivo, físico e social, pois representa uma motivação natural que instiga nos seres humanos o interesse de buscar novidades, aprender e criar.

A Teoria da Integração Organísmica (TIO) estuda a motivação extrínseca propondo quatro níveis de regulação (de externa à interna). Ryan e Deci (2000, p. 55) defendem a importância da motivação extrínseca quando apontam que, na sociedade, o dia a dia das pessoas envolve muitas atividades que não são intrinsicamente motivadas. Entretanto, quando as pessoas aprendem a valorizar essas atividades elas estão internalizando a motivação extrínseca. Entre os quatro niveis de regulação da motivação extrínseca, a mais superficial é a regulação externa, quando a pessoa age por um estímulo externo; na regulação introjetada a pessoa age por culpa, ou pressão interna (como se levasse as demandas externas para dentro de si); a regulação identificada é quando a pessoa aceita os motivos para realizar determinada ação, portanto já é mais internalizada; por fim a regulação integrada é o nivel mais autodeterminado de motivação extrínseca e o que mais se aproxima de uma motivação intrínseca, quando a pessoa entende e valoriza determinada ação ou atividade.

A Teoria da Orientação de Causalidade (TOC) estuda o comportamento dos indivíduos no mundo social defendendo que cada pessoa pode ter mais tendência a um tipo de orientação, que pode ser: orientação autônoma (que a faz agir por interesse e valorização e está relacionada a motivações autônomas), orientação controlada (que a faz agir por pressões externas e está relacionada 
a motivações controladas) ou orientação impessoal (quando a pessoa se sente incompetente e está relacionada à desmotivação) (Ryan; Deci, 2004, p. 21).

A Teoria das Metas e Conteúdos (TMC) está relacionada ao que se quer atingir com determinada ação. Quando o indivíduo se baseia em metas intrínsecas está preocupado com crescimento pessoal, saúde e contribuição para a comunidade, e isso gera consequências positivas tanto para ele quanto para a sociedade. Já as metas extrínsecas estão relacionadas a status, riqueza, fama, beleza, e essas metas não conseguem satisfazer as necessidades psicológicas básicas e por isso acabam afetando o bem-estar e a saúde psicológica do individuo (Vansteenkiste; Verstuyf; Lens, 2009, p. 156-157).

A Teoria da Motivação nos Relacionamentos (TRM) é a mais nova de todas as miniteorias, tendo sido iniciada em 2015. Essa teoria propõe estudar os relacionamentos e como eles se envolvem com as necessidades psicológicas básicas. Costa, Ntoumanis e Bartholomew (2015, p. 12) defendem que os relacionamentos podem promover a satisfação, a insatisfação ou a frustração das necessidades. A insatisfação ocorre com indivíduos que preferem ficar sozinhos a se relacionar e não é tão prejudicial quanto a frustração das necessidades, que é quando o individuo é rejeitado ou isolado e por isso fica sozinho; neste caso as necessidades psicológicas são minadas por outras pessoas. Os relacionamentos podem, então, gerar nos indivíduos sensibilidade interpessoal (e.g. quando a pessoa tem dificuldade de se relacionar, ou se sente desconfortável na frente de outros) ou competência interpessoal (e.g. quando a pessoa tem facilidade para expor seus próprios sentimentos e dá suporte para que outros também exponham os seus). Segundo Costa, Ntoumanis e Bartholomew (2015, p. 14), a frustração das necessidades é a que mais gera a sensibilidade interpessoal, enquanto a satisfação das necessidades é a que mais gera a competência interpessoal.

A TAD também é utilizada em estudos direcionados para determinadas áreas, como a da educação. Reeve (2006b, p. 228) propõe o ensino baseado na promoção de autonomia, dizendo que os professores podem ter um estilo motivacional controlador ou um estilo motivacional promotor da autonomia dos alunos. O professor controlador vai motivar seus alunos com a regulação externa (e.g. pressão, prazos, metas externas). Já o professor promotor da autonomia auxilia os alunos a desenvolverem autonomia e isso gera no aluno gosto pela escola, criatividade, engajamento, emotividade, elevação da motivação intrínseca, entre outros beneficios. Estudos como o de Reeve (2006b) e Reeve e Jang (2006) proporcionam uma visão mais ampliada de qual seria o comportamento de um professor promotor da autonomia em relação aos alunos.

\section{A Motivação no Método SuzuKi e A TEORIA DA AUTODETERMINAÇÃO}

Suzuki falava bastante sobre a questão da motivação dos alunos e qual o papel dos professores e pais em relação a isso, tema recorrente na sua bibliografia e na de seus seguidores. Para ele, os professores deveriam trabalhar junto com os pais desenvolvendo um ambiente propício à motivação do aluno 
(Starr, 1976, p. 9). Os elementos motivacionais encontrados na bibliografia de Suzuki e na de seus seguidores foram organizados na pesquisa de Santos (2016, p. 30-40) em cinco categorias motivacionais principais, no intuito de deixar mais claras as propostas de Suzuki para a motivação dos alunos.

Um dos intuitos da pesquisa era o de avaliar o quanto dos fatores motivacionais considerados por Suzuki são ainda válidos e atuais na visão de professores que trabalham com o Método Suzuki nos dias de hoje. Para isso foi realizado um questionário com professores capacitadores latino-americanos (PCLA), que são atualmente oito no total (quatro na Argentina, dois no Brasil e dois no Peru). O questionário enviado aos PCLA foi baseado nas cinco categorias motivacionais com perguntas que abordavam os seus principais aspectos. Os resultados obtidos a partir das respostas dos PCLA mostraram que os professores concordam com a importância da grande maioria dos fatores motivacionais levantados por Suzuki. Um dado que mostra que os elementos de motivação propostos por Suzuki são válidos e utilizados por professores experientes no ensino musical e no Método Suzuki.

Uma das questões lançadas funcionou, particularmente, como um resumo e conclusão de todas as outras. A mesma pedia aos PCLA que elencassem, em ordem de importância, dez elementos motivacionais que haviam sido abordados nas outras questões. Segundo a análise do resultado das respostas, que pode ser visualizado na Figura 1, os PCLA consideram que os professores têm o papel mais importante na motivação dos alunos, seguidos dos pais. Dado interessante, pois se aproxima da opinião de Suzuki de que professores e pais deveriam trabalhar juntos na motivação dos alunos.

\begin{tabular}{|l|l|l|l|l|l|l|l|l|l|l|l|l|}
\hline \\
\hline
\end{tabular}

Figura 1: Ordem de relevância dos elementos motivacionais segundo respostas dos PCLA (Santos, 2016, p. 91). 
Na etapa de análise dos dados da pesquisa também foi utilizada a Teoria da Autodeterminação (TAD) para verificar a validade das propostas motivacionais de Suzuki, a partir da visão de uma teoria da psicologia motivacional. Assim, buscou-se correlacionar os conceitos motivacionais propostos na TAD com os elementos de motivação do aluno elencados nas cinco categorias motivacionais do Método Suzuki. Os resultados foram surpreendentes, pois pôde-se encontrar muitas congruências nessa comparação. Não foram encontradas divergências e, além disso, constatou-se que a TAD pode trazer complementos para as ideias motivacionais de Suzuki. A seguir serão apresentadas brevemente as cinco categorias e como elas se relacionam com a TAD.

A primeira categoria foi nomeada "Despertar/nutrir o desejo de tocar". Suzuki considera que o desejo de tocar o instrumento deve ser despertado muito cedo na criança, uma vez que, segundo a sua metodologia, elas iniciam os seus estudos a partir de 3 ou até 2 anos. A audição das gravações das músicas que fazem parte do método é, para ele, uma das formas de despertar e nutrir esse desejo (Suzuki, 1982, p. 49). Além disso, a criança ser inserida no ambiente onde ela veja outras crianças e mesmo a mãe ou pai ${ }^{7}$ tocando desperta nela o desejo de imitar, o intuito é que a criança fale: "Eu também quero tocar" (Suzuki, 2008, p. 126).

Essa categoria se relaciona na TAD com a formação da motivação intrínseca na criança que, segundo Deci e Ryan (1985, p. 127), vem da junção de duas fontes: as habilidades inatas e a experiência vivenciada e proporcionada pelo ambiente em que ela vive, assim, somente o que é oferecido pelo ambiente pode se desenvolver nas crianças. As sugestões de Suzuki de colocar a criança em um ambiente em que ela fique imersa na música - seja por meio da audição, ou vendo sua mãe ou pai e outras crianças tocando - é uma forma de fazer com que a criança desenvolva o desejo (motivação) intrínseco de tocar um instrumento e se envolver com a música. Essa categoria também se relaciona com a necessidade de se sentir pertencente da TNB (Ryan; Deci, 2004 , p. 7), pois a criança, ao ser inserida no ambiente onde a mãe e/ou outras crianças estão tocando, sente a necessidade de pertencer a esse grupo.

A segunda categoria, "O prazer de aprender, o prazer de ensinar", está relacionada com o prazer que tanto o aluno como o professor e os pais devem sentir e considerar durante o processo de aprendizagem do aluno. No caso dos alunos, Suzuki (1981, p. 21) avalia que as crianças se desenvolvem melhor quando estão se divertindo, e acredita ser muito importante que o aluno aprecie tocar seu instrumento (Suzuki, 1982, p. 71). Em se tratando dos pais, Suzuki retorna a espelhar o que acontece na aprendizagem da língua materna: cada conquista do bebê (um balbucio, uma nova palavra, etc.) é acompanhada por entusiasmo e incentivo dos pais. Assim também deve acontecer no aprendizado musical, sendo que o interesse no desenvolvimento

\footnotetext{
7 Suzuki costumava ensinar um dos pais a segurar o instrumento e mesmo tocar uma peça nas primeiras aulas para que pudesse auxiliar o filho com maior propriedade nos estudos em casa. Muitos professores mantêm essa prática atualmente (Starr, 1976, p. 9).
} 
musical do filho faz toda a diferença para que a criança se sinta estimulada no estudo (Starr, 1976, p. 9-10). Em relação aos professores, Suzuki deixa uma mensagem bem clara: a de que o professor deve realmente amar ensinar e encarar a aula como um momento prazeroso, proporcionando ao aluno um ambiente e uma aula agradável (Starr, 1976, p. 10; Suzuki, 1998, p. 11).

Sob a perspectiva da TAD, podemos considerar que a motivação decorrente do prazer e apreciação do próprio aluno quando toca seu instrumento está relacionada ao sentimento de competência e autonomia, que são duas das três necessidades psicológicas básicas, segundo a TNB, o que eleva também seus niveis de motivação intrínseca, segundo a TAC (Ryan; Deci, 2004, p. 11). Quanto aos pais e professor, ao sentirem prazer no processo estão transmitindo ao aluno senso de pertencimento (TNB). Também se relaciona ao conceito de parentesco proposto por Reeve (2006b, p. 222-223), que acontece nas boas relações entre alunos e professores e faz com que o aluno se sinta especial e importante no momento em que o professor demonstra afeto, é caloroso e o aprova.

A terceira categoria, "Prática em casa", trata sobre esse assunto que é um tanto complexo e com o qual muitos pais sentem dificuldade, pois eles acabam se tornando os principais responsáveis por fazerem os filhos realizarem a prática diariamente, e para que essa prática se torne um fator positivo para a motivação do aluno ela precisa ser prazerosa e não forçada. Segundo Mills e Murphy (1973, p. 64, tradução nossa): "A prática deve ser agradável de forma que a criança a aprecie suficientemente para praticar mais uma vez." Entretanto, Suzuki (1982, p. 45-50) deixa algumas dicas sobre como os professores podem auxiliar os pais, orientando-os a como preparar o ambiente para que o filho se sinta estimulado a estudar, colocando as gravações das músicas regularmente e levando o filho para assistir às aulas de outros alunos ou participar das aulas em grupo, por exemplo. Além disso, o próprio professor pode mostrar e explicar ao aluno o valor do estudo e lembrar de sempre cobrar na aula o que pediu para o aluno estudar durante a semana. Suzuki também defende que o tempo de estudo deve ser proporcional à capacidade de concentração da criança, nem que isso signifique pelo menos no início dois minutos, e que podem ser realizados vários pequenos estudos ao longo do dia nos quais a criança esteja realmente compenetrada (Mills; Murphy, 1973, p. 66).

A indicação de Suzuki de que o momento da prática deve ser prazeroso para o aluno se relaciona com a TAD na medida em que essa prática busca promover os recursos motivacionais internos do aluno. Professor e pais devem se preocupar com o interesse, esforço e prazer do aluno no momento do estudo, podendo usar estratégias que coordenem a prática com preferências, interesses e competências do aluno. Esta categoria se relaciona fortemente com a TIO, pois quando o valor da prática é internalizado numa forma boa de motivação extrínseca os resultados são uma melhor aprendizagem, desenvolvimento e persistência, e para isso podem ser utilizadas metas intrínsecas,

\footnotetext{
8 No original: "Practicing should be pleasant so that the child will enjoy it sufficiently to practice another time."
} 
segundo a TMC. Entretanto, a prática forçada com o uso de recompensas ou ameaças por parte dos pais pode estimular motivações externas fracas - regulação externa ou introjetada (Ryan; Deci, 2000, p. 61-62).

A quarta categoria trata sobre a "Socialização". Para Suzuki (1982, p.49) a socialização era um ponto importante para a motivação do aluno e por isso ele possibilitava vários momentos em que os alunos pudessem se encontrar, tocar juntos e assistir à performance um dos outros. Isso acontecia nas aulas individuais, onde alunos podiam assistir à aula um dos outros funcionando como uma masterclass, nas aulas em grupo e nos concertos e recitais. Para Suzuki (1998, p. 11-12), quando os alunos assistem às aulas de outros alunos, eles estão aprendendo com essa performance e também com a instrução do professor. Isso é um grande ganho, principalmente quando a aula está sendo dada a um aluno mais avançado. Suzuki (1982, p. 49) dava muito valor para a participação das crianças nas aulas em grupo. Elas são a oportunidade de os alunos tocarem uns com os outros, sendo que essas aulas normalmente têm um caráter mais divertido. O divertimento auxilia na motivação ao mesmo tempo que as crianças aprendem a tocar em grupo. Os recitais e/ou concertos poderiam ser pequenos recitais em casa para familiares, na aula para o professor, recitais de alunos ou apresentações coletivas. Segundo Suzuki (1982, p. 136), esse tipo de atividade é importante, pois a criança aprende a apreciar tocar o instrumento, assiste aos amigos tocando e é assistido, recebe elogios e aplausos após a performance, e também a motiva a estudar em casa para tocar bem na apresentação.

Essa categoria se relaciona com a necessidade de pertencimento da TNB, que inclui o desejo de se sentir pertencente a comunidades/grupos (Ryan; Deci, 2004, p. 7). Reeve (2006a, p. 77) complementa dizendo que a satisfação da necessidade de pertencer gera sentimentos de afeto, apreciação, aceitação e valorização de uns pelos outros. Com o senso de pertencimento satisfeito, as motivações externas também são internalizadas mais facilmente, pois, segundo Ryan e Deci (2000, p. 64), as pessoas se sentem dispostas a realizar determinada atividade quando esta é valorizada por outros com quem elas se sentem conectadas. Reeve (2006b, p. 231) ainda complementa dizendo que um professor promotor da autonomia dá oportunidades para os alunos interagirem entre si e para os alunos se expressarem, o que se relaciona com as aulas em grupo e com os recitais e apresentações.

A quinta categoria, "Elogios e correções", é um dos pontos mais comentados por Suzuki (1981, p. 20, 1982, p. 41, 1990, p. 60-61, 1998, p.11) e por seus seguidores (Mills; Murphy, 1973, p. 66; Starr, 1976, p. 9; Wickes, 1982, p. 40-43). Para Suzuki o elogio vindo do professor e dos pais era uma importante ferramenta para a motivação do aluno. Ele defendia que o professor deve constantemente elogiar o esforço do aluno e que as correções são mais bem recebidas pelos alunos quando vêm após um elogio do que após uma crítica (Suzuki, 1982, p. 41). Entretanto, o elogio deve ser sincero e honesto, elogiando algo que realmente aconteceu na performance do aluno (Wickes, 1982 , p. 43). Starr (1976, p. 9) relata que geralmente nas aulas de Suzuki o elogio vinha acompanhado de uma frase para instigar o aluno a melhorar, 
como por exemplo: “Ele nunca dizia, 'Não, isso não está bom', mas somente 'Bom. Você pode fazer isso melhor? Vamos tentar novamente"'9 (Starr, 1976, p. 9, tradução nossa).

A TAD fala sobre o elogio como uma forma de feedback positivo, e que este ajuda a satisfazer a necessidade de competência (TNB), o que também acaba elevando a sua motivação intrínseca, segundo a TAC (Reeve, 2006a, p. 94). Para Reeve (2006b, p. 229), quando o professor elogia o aluno ele promove suas motivações intrínsecas e suas motivações extrinsecas internalizadas. Sobre a correção, Bzuneck (2010, p. 30-33) afirma que esta precisa ser aplicada de forma que não prejudique a motivação do aluno, e Reeve (2006b, p. 229) fala sobre como o professor deve guiar o aluno explicando-lhe a melhor forma de realizar alguma atividade, aqui, no caso, tocar um instrumento.

\section{CONSIDERAÇÕES FINAIS}

Este artigo teve o propósito de trazer alguns dos principais dados dos resultados da pesquisa de Santos (2016). Foi apresentada a fundamentação científica do Método Suzuki realizada, trazendo estudos recentes das áreas de psicologia, cognição, educação e educação musical que corroboram os aspectos que Shinichi Suzuki propôs à sua metodologia de forma empírica, ainda na década de 1930. Ademais, foram apresentados os elementos motivacionais considerados importantes para a motivação do aluno na visão de Shinichi Suzuki, como eles foram organizados em cinco principais categorias e depois validados e atualizados por meio da pesquisa realizada com os PCLA. Por fim, foi exposto, de forma resumida, como elementos motivacionais propostos no Método Suzuki se relacionam com as propostas da Teoria da Autodeterminação, evidenciando que as estratégias motivacionais utilizadas por professores que utilizam esta metodologia são coerentes e válidas segundo a visão de uma teoria motivacional da psicologia cognitiva.

Pode-se concluir que, de forma geral, o presente artigo traz informações que podem contribuir para a área de pesquisa sobre motivação na educação musical, abordando o tema de forma mais específica para professores de instrumento. Este estudo traz à tona a importância de o professor de instrumento buscar ferramentas e formações que vão além da parte técnica do próprio instrumento. Como professores, é necessário adentrar áreas além da música, como educação e psicologia, áreas que nos preparam para a prática real do ensino e para a boa relação com nossos alunos, para que saibamos melhor orientá-los e guiá-los.

Os resultados da pesquisa de Santos (2016) trouxeram elementos motivacionais importantes que podem ajudar professores de música na prática com seus alunos. Assim, podemos deixar sugestões de estratégias motivacionais para serem utilizadas por professores de música (que utilizam ou não o Método Suzuki). Como professores devemos estar atentos à nossa postura,

\footnotetext{
9 No original: "He never said, 'No, that is not good', but only 'Good. Can you do this better? Let's try again'."
} 
proporcionando um ambiente agradável para os alunos, pois assim são transmitidos acolhimento e afeto, fazendo com que eles se sintam importantes. Podemos de alguma forma envolver os pais no processo, de forma que eles apoiem e incentivem o filho, o que trará sentimentos de segurança e valorização ao aluno. É importante também que os alunos participem de momentos de socialização para que se sintam pertencentes a um grupo. Devemos lembrar de utilizar o elogio como forma de indicar para o aluno o que ele está fazendo certo e que deve prosseguir nesse caminho. Também podemos orientar os pais para que possam conduzir o estudo dos filhos em casa de maneira prazerosa e sempre lembrar o aluno do valor do estudo. Por fim, como professores devemos estar atentos aos alunos, nos preocupando com o seu interesse, esforço e prazer no aprendizado musical.

\section{REFERENCIAS}

ARAÚJO, Rosane C. Motivação e ensino de música. In: ARAÚJO, Rosane C.; ILARI, Beatriz S. (org.). Mentes em música. Curitiba: Editora UFPR, 2013. p. 111-130.

Motivação para prática e aprendizagem da música. In: ARAÚJO, Rosane C.; RAMOS, Danilo (org.). Estudos sobre motivação e emoção em cognição musical. Curitiba: Editora UFPR, 2015. p. 45-58.

ARAÚJO, Rosane C.; CAVALCANTI, Célia R.; FIGUEIREDO, Edson. Motivação para a prática musical no contexto do ensino superior: três possibilidades de abordagens discursivas. Revista da Abem, Porto Alegre, v. 24, p. 34-44, 2010.

BROWSE by instrument. In: SUZUKI ASSOCIATION OF THE AMERICAS. [S. l.]: Suzuki Association of the Americas, 2018. Disponivel em: https:// suzukiassociation.org/events/instr/. Acesso em: 29 jul. 2018.

BZUNECK, José A. Como motivar os alunos: sugestões práticas. In: BORUCHOVITCH, Evely; BZUNECK, José A.; GUIMARÃES, Sueli E. R. (org.). Motivação para aprender. Petrópolis: Vozes, 2010. p. 13-42.

CERNEV, Francine K. A motivação de professores de música sob a perspectiva da teoria da autodeterminação. 2011. Dissertação (Mestrado em Educação Musical) - Instituto de Artes, Universidade Federal do Rio Grande do Sul, Porto Alegre, 2011.

Aprendizagem musical colaborativa mediada pelas tecnologias

digitais: motivação dos alunos e estratégias de aprendizagem. 2015. Tese (Doutorado em Educação Musical) - Instituto de Artes, Universidade Federal do Rio Grande do Sul, Porto Alegre, 2015. 
COSTA, Sebastiano; NTOUMANIS, Nikos; BARTHOLOMEW, Kimberley J. Predicting the brighter and darker sides of interpersonal relationships: does psychological need thwarting matter?. Motivation and Emotion, [s. l.], v. 39, p. 11-24, 2015.

DECI, Edward L.; RYAN, Richard M. Intrinsic motivation and selfdetermination in human behavior. New York: Plenum Press, 1985.

Self-determination theory: a macrotheory of human motivation, development, and health. Canadian Psychology, [s. l.], v. 49, n. 3, p. 182185, 2008.

ENGELMANN, Erico; RUFINI, Sueli E. A motivação do estudante de artes: uma analise orientada pela Teoria da Autodeterminação. In: ARAÚJO, Rosane C.; RAMOS, Danilo (org.). Estudos sobre motivação e emoção em cognição musical. Curitiba: Editora UFPR, 2015. p. 237-252.

ERICSSON, K. Anders; CHARNESS, Neil. Expert performance: its structure and acquisition. American Psychologist, Washington DC, v. 49, n. 8, p. 725$747,1994$.

FIGUEIREDO, E. A. F. V. Um estudo sobre a teoria da autodeterminação no contexto do ensino do violão. 2010. Dissertação (Mestrado em Música) - Setor de Artes, Comunicação e Design, Universidade Federal do Paraná, Curitiba, 2010.

GARDNER, Howard. Estruturas da mente: a teoria das inteligências múltiplas. Porto Alegre: Artmed, 2007.

ILARI, Beatriz S. Bebês também entendem de música: a percepção e a cognição musical no primeiro ano de vida. Revista da Abem, Porto Alegre, v. 7, p. 83-90, 2002.

Shinichi Suzuki: a educação do talento. In: ILARI, Beatriz; MATEIRO, Teresa (org.). Pedagogias em educação musical. Curitiba: Ibpex, 2011. p. 185-218.

McPHERSON, Gary E.; GABRIELSSON, Alf. From sound to sign. In: PARNCUTT, Richard; McPHERSON, Gary E. (ed.). The science and psychology of music performance: creative strategies for teaching and learning. New York: Oxford, 2002. p. 99-115.

MILLS, Elizabeth; MURPHY, Therese C. (ed.). Motivation. In: MILLS, Elizabeth; MURPHY, Therese C. (ed.). The Suzuki concept: an introduction to a successful method for early music education. San Francisco: Diablo Press, 1973. p. 63-67. 
NILES, Laurie. The method and the movement. The Strad, [s. l.], v. 123, n. 1469, p. 34-40, 2012.

REEVE, Johnmarshall. Motivação e emoção. 4. ed. Rio de Janeiro: LTC, $2006 a$.

Teachers as facilitators: what autonomy-supportive teachers do and why their students benefit. The Elementary School Journal, [s. l.], v. 106, n. 3, p. 225-236, 2006b.

REEVE; Johnmarshall; JANG, Hyungshim. What teachers say and do to support students' autonomy during a learning activity. Journal of Educational Psychology, [s. l.], v. 98, n. 1, p. 209-218, 2006.

RYAN, Richard M.; DECI, Edward L. Intrinsic and extrinsic motivations: classic definitions and new directions. Contemporary Educational Psychology, [s. l.], v. 25, p. 54-67, 2000.

Overview of self-determination theory: an organismic dialectical perspective. In: DECI, Edward L.; RYAN, Richard M. (ed.). Handbook of selfdetermination research. Rochester: The University of Rochester Press, 2004. p. 3-33.

SANTOS, Marina Maugeri. A motivação no Método Suzuki e a prática de professores capacitadores latino-americanos: um estudo sob a perspectiva da Teoria da Autodeterminação. 2016. Dissertação (Mestrado em Música: Teoria, Criação e Prática) - Instituto de Artes, Universidade Estadual de Campinas, Campinas, 2016.

STARR, William. The Suzuki violinist: a guide for teachers and parents. Miami: Summy Birchard, 1976.

SUZUKI, Shinichi. Ability development from age zero. Miami: SummyBirchard, 1981.

Where love is deep. New Albany: World-Wide Press, 1982.

Man and talent: search into the unknown. Ann Arbor: Shar Products Company, 1990.

. Young children's talent education \& its method. Miami: SummyBirchard, 1996.

Discovery of the law of ability and the principle of ability development: proof that talent is not inborn. In: SUZUKI, Shinichi. Shinichi Suzuki: his speeches and essays. Miami: Summy-Birchard, 1998. p. 1-17.

Educação é amor: o método clássico da educação do talento. 3. ed. Santa Maria: Pallotti, 2008. 
TEACHER trainig. In: SUZUKI ASSOCIATION OF THE AMERICAS. [S. l.]: Suzuki Association of the Americas, 2016. Disponivel em: https:// suzukiassociation.org/teachers/training. Acesso em: 22 nov. 2016.

TOURINHO, Cristina. Ensino coletivo de instrumentos musicais: crenças, mitos, princípios e um pouco de história. In: ENCONTRO ANUAL DA ABEM, 16., 2007, Campo Grande. Anais [...]. Campo Grande: Abem, 2007. $1 \mathrm{CD}-\mathrm{ROM}$.

TSITSAROS, Christos. Practicing at the elementary level. In: LYKE, James; ENOCH, Yvonne; HAYDON, Geoffrey (ed.). Creative piano teaching. Champaign: Stipes, 1996. p. 121-130.

VANSTEENKISTE, Marten; VERSTUYF, Joke; LENS, Willy. What is the usefulness of your schoolwork?: the differential effects of intrinsic and extrinsic goal framing on optimal learning. Theory and Research in Education, [s. l.], v. 7, n. 2, p. 155-163, 2009.

WHAT is music cognition. Palestra de David Huron. [S. l.: s. n.], 2017. 1 vídeo (19 min). Disponivel em: https://vimeo.com/197829351. Acesso em: 11 out. 2017.

WICKES, Linda. The genius of simplicity. Miami: Summy-Birchard, 1982. 
Marina Maugeri Santos é doutoranda e mestra pela Universidade Estadual de Campinas (Unicamp). Bacharel em Música com habilitação em Violino pela Faculdade Santa Marcelina (Fasm). Iniciou seus estudos de violino no Centro Suzuki de Campinas, com os professores Profa Dra Shinobu Saito e Prof. Me. Fábio dos Santos. Foi aluna também da Profa Dra Eliane Tokeshi e do Prof. Dr. Luiz Amato. Vem se especializando como professora e pesquisadora do Método Suzuki, desenvolvendo pesquisas sobre pedagogia do instrumento, com foco em violino e cordas. Atualmente é professora de violino e musicalização infantil no Centro Suzuki de Campinas e coordenadora do projeto Música na Primeira Infância, na Amigos da Criança (Amic). https://orcid.org/0000-0003-3079-9362.

Adriana do Nascimento Araújo Mendes é doutora em Música em Fundamentos Teóricos pela Universidade Estadual de Campinas (Unicamp), mestre em Música pela Syracuse University, EUA, e bacharel em Piano pela Universidade Federal do Rio de Janeiro (UFRJ). É professora do curso de Graduação em Música e do Programa de Pós-Graduação em Música da Unicamp, onde ministra disciplinas da área de Educação Musical e desenvolve pesquisas sobre a formação do professor de música, com ênfase em "Formação de professores para a escola de educação básica", "Tecnologias e ensino musical", "Ensino musical e inclusão", "Estágio supervisionado" e "Ensino coletivo de piano". Atualmente é coordenadora do curso de Graduação em Música - Bacharelado e Licenciatura - e coordenadora de área do Residência Pedagógica de Arte da Unicamp. É coordenadora do projeto de extensão Oficina de Musicalização desde 2009, membro da Isme e Abem e integrante do grupo de pesquisa Tecnologias Aplicadas à Criação, à Expressão e ao Ensino Musicais. https://orcid.org/0000-0002-9730-2202

Luiz Britto Passos Amato é bacharel pela Universidade de São Paulo e concluiu o mestrado e graduate diploma pelo New England Conservatory de Boston, EUA. Em 1996 doutorou-se pela California University, EUA, e durante esse período foi membro do quarteto em residência dessa universidade, com o qual participou de vários festivais e concertos pelos Estados Unidos, Europa e Brasil. É ganhador de dois prêmios APCAs como camerista e foi o violino principal da Orquestra Sinfônica Municipal de São Paulo, da Amazonas Filarmônica e da Orquestra Jazz Sinfônica. Hoje, é professor da Universidade Estadual Paulista (Unesp). https://orcid.org/0000-0003-1601-6966 